\title{
Pneumonia immunization in older adults: review of vaccine effectiveness and strategies
}

This article was published in the following Dove Press journal:

Clinical Interventions in Aging

31 October 2012

Number of times this article has been viewed

\section{Usama Assaad ${ }^{2}$ \\ Ibrahim El-Masri² \\ Jahan Porhomayon 1,3 \\ Ali A El-Solh ${ }^{1-4}$}

'The Veterans Affairs Western New York Healthcare System, Buffalo, NY, USA; ${ }^{2}$ Division of Pulmonary, Critical Care, and Sleep Medicine, ${ }^{3}$ Department of Anesthesia,

${ }^{4}$ Department of Social and Preventive Medicine, State University of New York at Buffalo School of Medicine and Biomedical Sciences and School of Public Health and Health Professions, Buffalo, NY, USA
Correspondence: Ali A El-Solh Medical Research, BIdg 20 (I5I) VISN02, VA Western New York Healthcare System, 3495 Bailey Avenue, Buffalo, NY 14215-1199, USA

$\mathrm{Tel}+\mathrm{I} 7168627366$

Fax + I 4256754502

Email solh@buffalo.edu

\begin{abstract}
Vaccination remains the primary preventive strategy in the elderly against Streptococcus pneumoniae and influenza infections. The effectiveness of this strategy in preventing pneumonia has been in doubt despite the increase in vaccination coverage among older adults. Randomized controlled trials (RCTs) and observational studies aimed at determining clinical outcomes and immune response following pneumococcal vaccination have yielded conflicting results. The protective efficacy of pneumococcal vaccination against pneumonia in older adults has not been firmly established due to a lack of RCTs specifically examining patients $\geq 65$ years of age. Similarly, the reported benefits of influenza vaccination have been derived from observational data. The assessment of clinical benefit from influenza vaccination in the elderly population is complicated by varying cohorts, virulence of the influenza strain, and matching of vaccine and circulating viral strains. The presence of selection bias and use of nonspecific end points in these studies make the current evidence inconclusive in terms of overall benefit. The development of more immunogenic vaccines through new formulations or addition of adjuvants holds the promise of revolutionizing delivery and improving efficacy. Dismantling existing barriers through education, providing technology assistance predominantly to developing countries, and establishing clear regulatory guidance on pathways for approval are necessary to ensure timely production and equitable distribution.
\end{abstract}

Keywords: pneumococcal vaccine, influenza vaccine, vaccine effectiveness, pneumonia, older adults

\section{Introduction}

The description by Sir William Osler, "Pneumonia remains now, as then, the most serious acute disease with which physicians have to deal; serious because it attacks the old, the feeble ... persons who are not able to withstand the sudden sharp onset of the malady," still stands the test of time. ${ }^{1}$ Over a century later, pneumonia remains a major cause of morbidity and mortality in the elderly. In 2005, pneumococcal disease and influenza were the eighth-leading cause of death in the United States and the leading cause of infection-related mortality for all age-groups. ${ }^{2}$ An estimated $90 \%$ of deaths caused by these diseases occur among adults 65 years of age or older. ${ }^{3,4}$ Nonbacteremic pneumococcal pneumonia accounts for approximately $30 \%$ of all patients hospitalized with community-acquired pneumonia, while annual influenza epidemics result in an average of more than 18,000 deaths and 48,000 hospitalizations among older persons in the United States, ${ }^{5}$ more than all other vaccine-preventable diseases combined. It has been estimated that the total annual excess cost of hospital-treated pneumonia as a primary diagnosis in the elderly fee-for-service Medicare population in 2010 
exceeded $\$ 7$ billion. ${ }^{6}$ Most of the direct expense is attributed to inpatient costs, including hospitalization, length of stay, room and board, and physician services. The purpose of this manuscript is to provide an overview of the current pneumococcal and influenza effectiveness in the elderly and delineate future immunization strategies to reduce the rate of pneumonia in this age-group.

\section{Pneumococcal vaccine}

Based on the most recent recommendations, the Advisory Committee on Immunization Practices (ACIP) advocates a single dose of 23-valent pneumococcal capsular polysaccharide vaccine (PPSV23) for all persons aged 65 years and older. In addition, for adults aged 19-64 years, PPSV23 should be administered to those who are immunocompromised (including chronic renal failure or nephrotic syndrome); those with functional or anatomic asplenia; those who are immunocompetent and have chronic conditions such as alcoholism, diabetes mellitus, or chronic lung disease; those who are smokers; and those with cochlear implants or cerebrospinal fluid leaks. A repeat vaccination is recommended for persons $\geq 65$ years of age who received their first vaccine at $<65$ years of age, but revaccination is not recommended for persons who received their first vaccination at $\geq 65$ years of age unless the patient is immunocompromised or asplenic. Furthermore, a one-time revaccination after 5 years is recommended for older adults with chronic renal failure, nephritic syndrome, or immunosuppressive conditions. Although not yet recommended by the ACIP, 13 -valent pneumococcal conjugate vaccine (PCV13) is available for use among adults aged 50 years and older in accordance with the package insert.

The currently available pneumococcal polysaccharide vaccine (PPV) was licensed in 1983, replacing the 14-valent vaccine introduced in 1977 . The 23 -valent vaccine includes serotypes $1,2,3,4,5,6 \mathrm{~B}, 7 \mathrm{~F}, 8,9 \mathrm{~N}, 9 \mathrm{~V}, 10 \mathrm{~A}, 11 \mathrm{~A}, 12 \mathrm{~F}$, $14,15 \mathrm{~B}, 17 \mathrm{~F}, 18 \mathrm{C}, 19 \mathrm{~A}, 19 \mathrm{~F}, 20,22 \mathrm{~F}, 23 \mathrm{~F}$, and $33 \mathrm{~F}$; some of these serotypes have a fair cross-reactivity with serotypes that are not contained in the vaccine (namely $6 \mathrm{~B}$, $6 \mathrm{~A}, 15 \mathrm{~B}$, and $15 \mathrm{~A}$ ), providing potential coverage of more than 23 serotypes. These serotypes in the vaccine represent $85 \%-90 \%$ of serotypes that cause invasive pneumococcal disease in the United States. ${ }^{7}$ Since it is made up of polysaccharide and nonprotein antigens, the PPV induces an antibody response independent from $\mathrm{T}$ lymphocytes. These antigens induce type-specific antibodies that enhance opsonization, phagocytosis, and killing of pneumococci by leukocytes.
In most elderly patients, the antibody response to PPV immunization is adequate. ${ }^{8}$ The percentage of elderly patients with postvaccination antibody concentration $>$ twofold ranges from $84 \%$ for serotype $18 \mathrm{C}$, to $90 \%$ for serotypes $7 \mathrm{~F}$, $9 \mathrm{~V}$, and $19 \mathrm{~F}$. $^{9}$ However, antibody potency, as measured by the ratio of opsonization titer to antibody concentration, is significantly lower for elderly subjects for all serotypes. ${ }^{10}$ In addition, certain patients with underlying comorbidities may respond only partially to some of the 23 serotypes included in the vaccine. These patients usually exhibit impaired B-cell response and decreased avidity of induced antibodies, ${ }^{11,12}$ which limit the benefit of pneumococcal vaccination.

Normally, a steady decline in serotype-specific antibody titers occurs following vaccination, and prevaccination levels are generally reached within 5-10 years. ${ }^{7}$ An anamnestic response does not occur at revaccination, and the overall increase in antibody levels is lower after revaccination than following primary vaccination. ${ }^{13}$ In two recent studies, patients who had received PPSV23 3-5 years previously had modestly lower opsonophagocytic killing activity and total antibody responses at 30 and 60 days after revaccination with PPSV23 than did vaccine-naive recipients, although these differences were not statistically significant for most serotypes. ${ }^{14,15}$ The mechanism of this phenomenon, known as immune hyporesponsiveness, remains under investigation. ${ }^{16}$ One hypothesis stipulates activation of memory suppressor $\mathrm{T}_{\text {cells }}{ }^{14}$ while another suggests depletion of memory B cells. ${ }^{17}$ In the absence of an immune correlate of protection for pneumococcal infection in adults, the clinical significance of this phenomenon is yet to be determined.

The effectiveness of PPSV23 in reducing pneumonia and its complications in the elderly population remain controversial. ${ }^{18}$ The recommendation of PPSV23 was based on several clinical trials (ie, trials before 1980) and epidemiological studies, ${ }^{19,20}$ which found a protective effect against bacteremia and invasive disease. ${ }^{21}$ In contrast to observational studies $^{22-28}$ (Table 1), clinical investigations have shown a reduction in risk of death by pneumonia among younger adults and institutionalized elderly subjects vaccinated with PPSV23, ${ }^{29,30}$ but an effect on mortality from pneumonia has not been consistently documented for high-risk patients or noninstitutionalized older adults. ${ }^{21,31,32}$ Overall, eight clinical trials evaluated vaccine effectiveness against all-cause pneumonia in elderly people..$^{23,24,32-38}$ Only two ${ }^{23,35}$ demonstrated a reduction in risk in the group that received PPSV23. Both were derived from patients residing in skilled nursing facilities or long-term-care institutions. Gaillat et $\mathrm{al}^{23}$ evaluated 1686 residents of long-term-care institutions in France that 
Table I Observational studies related to the effectiveness of pneumococcal polysaccharide vaccine against all-cause pneumonia in older adults

\begin{tabular}{|c|c|c|c|}
\hline Reference & Vaccine valency & Study population & VE $(95 \% \mathrm{Cl})$ \\
\hline Kauffman 22 & 3 & $\begin{array}{l}\text { Long-term-care facility residents ( } 80 \% \text { were aged }>60 \text { years) } \\
\text { in New York City }\end{array}$ & $92(72-98)$ \\
\hline Gaillat et $\mathrm{a}^{23}$ & 14 & Residents of 48 long-term-care institutions in France & $79(53-91)$ \\
\hline Honkanen et a ${ }^{24}$ & 23 & Persons $\geq 65$ years of age in northern Finland & $-20(-50$ to 10$)$ \\
\hline Jackson et $\mathrm{a}^{27}$ & 23 & $\begin{array}{l}47,365 \text { Group Health Cooperative members } 65 \text { years } \\
\text { of age or older }\end{array}$ & HR I.04 (0.96-I.13) \\
\hline Vila-Corcoles et al ${ }^{25}$ & 23 & Community-dwelling individuals aged $\geq 65$ years & $45(12-66)$ \\
\hline Johnstone et $\mathrm{al}^{28}$ & 23 & 3415 admitted to six hospitals ( $83 \%$ aged $>65$ years) & HR I.24 (0.89-I.72) \\
\hline Vila-Corcoles et $\mathrm{al}^{26}$ & 23 & $\begin{array}{l}19 \text { participating primary health care centers and laboratory } \\
\text { departments of three tertiary hospitals ( } 74 \% \text { aged }>65 \text { years) }\end{array}$ & $46(25-61)$ \\
\hline
\end{tabular}

Abbreviations: VE, vaccine effectiveness; $\mathrm{HR}$, hazard ratio; $\mathrm{Cl}$, confidence interval.

were vaccinated with the 14 -valent PPV. The incidence of pneumonia was significantly reduced in the vaccinated group, but the mortality rate was unchanged. The study, however, did not include a placebo group, and neither subjects nor investigators were blinded to vaccine assignment. Those limitations have raised questions regarding the validity of the findings. ${ }^{39}$ In a more recent randomized, placebo-controlled study in nursing homes, Maruyama et $\mathrm{al}^{35}$ showed a $63.8 \%$ (95\% confidence interval [CI] 32.1-80.7) reduction of pneumococcal pneumonia and all-cause pneumonia mortality in vaccinated institutionalized elderly. These findings underscore the high risk of pneumococcal pneumonia in nursing homes and long-term-care facilities. None of the other six trials, including an NIH-sponsored trial involving 13,600 older adults ${ }^{33}$ and a trial in Finland involving 26,925 elderly adults, ${ }^{24}$ have demonstrated a significant vaccine-associated reduction in risk of all-cause pneumonia. Although many of these trials evaluated an end point of pneumococcal pneumonia, which was variably defined depending on the trial, none identified a reduction in the risk of pneumococcal pneumonia in prespecified analyses of all subjects. These clinical trials suggest that PPSV23 is not highly effective against nonbacteremic pneumococcal pneumonia, but do not rule out the possibility that the vaccine may lead to a reduction in risk of pneumococcal pneumonia that is not reflected by a detectable difference in risk of all-cause pneumonia evaluated in these trials. ${ }^{40}$

A Cochrane review concluded that while polysaccharide vaccines are effective in reducing the incidence of invasive pneumococcal disease among adults and immunocompetent elderly subjects aged $\geq 55$ years, PPSV23 does not appear to reduce the incidence of pneumonia or death in adults (with or without chronic diseases) or in the elderly ${ }^{41}$ Similarly, in the most recent published meta-analysis of randomized clinical trials carried out in elderly population, Huss and colleagues ${ }^{42}$ failed to show any protection of PPSV23 against all-cause pneumonia. In fact, there was little evidence of vaccine protection among elderly patients or adults with chronic illness in analyses of all trials (relative risk 1.04, 95\% CI $0.78-1.38$, for presumptive pneumococcal pneumonia; 0.89 , 95\% CI 0.69-1.14, for all-cause pneumonia; and 1.00, 95\% CI 0.87-1.14, for all-cause mortality). As a commentary, Fedson and Musher $^{7}$ argued that clinical trials of PPV were destined from the outset to be inconclusive because they suffered from methodologic problems and were too small to reliably show effects on all-cause pneumonia.

In 2000, the first pediatric pneumococcal vaccine - the 7-valent PCV (PCV7) - was licensed for prevention of pneumococcal disease in children younger than 5 years. The mechanism and advantages of conjugated PPVs have been covered recently in a review article on PCV7. ${ }^{43}$ Notably, PCV7 was found to be more immunogenic in the elderly than the PPSV23 and to exhibit a booster effect following a second vaccination a year later. ${ }^{17}$ Despite the early success of PCV7 and the near-total elimination of disease caused by vaccine serotypes in countries with routine immunization programs, significant concerns emerged from serotypes not included in PCV7. Among these serotypes were 1, 3, 5, 6A, 7F, 12F, 19A, 33, and $35 . .^{44-46}$ As a result, PCV13 was developed as a successor to PCV7 to address the need to provide protection against pneumococcal serotypes that have emerged as common causes of infection. PCV13 contains the serotypes found in PCV7, plus an additional six serotypes: 1, 3, 5, 6A, $7 \mathrm{~F}$, and $19 \mathrm{~A} .{ }^{47}$

The immunogenicity of PCV13 in the elderly was evaluated in two randomized multicenter studies (unpublished) conducted in the United States and Europe. ${ }^{48}$ The first trial enrolled adults aged $\geq 50$ years who received a single dose of either PCV13 or PPSV23. Functional antibody responses were measured 1 month after vaccination using 
an opsonophagocytic activity (OPA) assay. In those aged 60-64 years who were naive to PPSV23, PCV13 elicited OPA geometric mean antibody titers to the twelve serotypes common to both vaccines that were comparable to or higher than responses elicited by PPSV23. For serotype 6A, which is unique to PCV13, OPA antibody responses were higher after PCV13 vaccination than after PPSV23 vaccination. The second study included adults aged 70 years and older who previously had been immunized with a single dose of PPSV23 at least 5 years before enrollment. PCV13 elicited OPA responses that were noninferior to those elicited by PPSV23 for the 13 serotypes. Revaccination with PCV13 a year following initial administration of PCV13 resulted in OPA levels similar to those observed after the first dose. In contrast, subjects who were vaccinated with PPSV23 as the initial study dose displayed lower OPA antibody responses after subsequent administration of PCV13 compared to those who had received PCV13 as the initial vaccine, regardless of the level of the initial OPA response to PPSV23. ${ }^{48}$

On December 30, 2011, the FDA approved PCV13 for prevention of pneumonia and invasive disease caused by PCV13 serotypes among adults aged 50 years and older. The approval was granted under the FDA's Accelerated Approval regulation, which permits the agency to approve products for serious or life-threatening diseases on the basis of early evidence of a product's effectiveness that is "reasonably likely to predict clinical benefit." 49 The FDA recognized that the clinical efficacy of PCV13 against pneumococcal pneumonia in adults $\geq 65$ years of age had not been demonstrated. As part of the Accelerated Approval regulation process, Pfizer has agreed to conduct further studies to verify the anticipated benefit of the vaccine. To this end, a placebo-controlled trial involving approximately 85,000 persons aged 65 years and older who have never received PPSV23 is under way in the Netherlands to assess the protective benefit of PCV13 in the prevention of pneumococcal pneumonia. ${ }^{50}$ In addition, the FDA acknowledged that the full impact of routine PCV13 vaccination among children on the incidence of pneumococcal pneumonia in the elderly caused by serotypes outside those included in PCV13 is not known at this time. The most recent data from the United States demonstrate that approximately $15 \%$ of invasive pneumococcal disease is due to the ten strains included in the PPSV23 but not the PCV13. ${ }^{51}$ However, several prognostic models suggest reductions in the overall number of invasive pneumococcal disease (IPD) cases following PCV13 introduction, though of varying magnitude. This predicted reduction in the overall number of IPD cases following PCV13 introduction is attributed to the lower propensity to develop invasive disease given carriage of non-PCV13 serotypes in elderly age-groups, where most of the IPD cases occur. ${ }^{52}$ Furthermore, analysis extrapolated from observed PCV7 data using assumptions regarding serotype prevalence indicates that vaccination with PCV13 is anticipated to decrease the incidence of all-cause hospitalized and nonhospitalized pneumonia by approximately 948,000 and 1.93 million cases, respectively, over a 10 -year period. ${ }^{53}$

\section{Influenza vaccine}

The first population-scale use of an inactivated influenza vaccine was in US military personnel in 1945. It was not until the 1960s that the US health agencies pursued a policy of widespread influenza vaccination targeting the high-risk segment of the population, including patients with chronic conditions and elderly people. ${ }^{54}$ This came in response to the substantial morbidity and mortality during the 1957-58 pandemic. ${ }^{55}$ The recommendation was made on the basis of studies showing efficacy in young healthy recruits with clinical illness or seroconversion as primary measures of infection. In 1964, the ACIP reaffirmed this recommendation, but noted the absence of efficacy data. ${ }^{56}$

The benefit of influenza vaccination in the general elderly population (65 years and older), many of whom have chronic health conditions, has not been adequately assessed in randomized trials. The largest placebo-controlled randomized controlled trial (RCT) was conducted in the Netherlands during the 1991-92 influenza season. In that study, Govaert and colleagues ${ }^{57}$ randomized 1838 healthy volunteers aged $\geq 60$ years to either trivalent inactivated influenza vaccine or placebo. After stratifying by age, influenza vaccine effectiveness was estimated at 57\% (95\% CI 33\%-72\%) in subjects aged $60-69$ years, but only $23 \%$ in volunteers aged $\geq 70$ years (95\% CI 21\%-33\%). The authors suggested that the effectiveness of the vaccine wanes with aging consistent with immune senescence after the age of 70 years. Analysis of antibody responses to inactivated influenza vaccines lends support to this hypothesis, as elderly people mount an immune response about one-quarter to one-half that of younger adults. ${ }^{58}$ Two contemporary placebo-controlled trials of influenza vaccination in elderly people failed to demonstrate improved survival or reduced hospitalization. ${ }^{59,60}$ So far, it has not been possible to resolve conclusively the question of influenza vaccine effectiveness in this age-group. An RCT with death due to influenza as the outcome would be difficult to undertake because of the sample size required and the problem of obtaining ethics approval for an established public-health intervention. ${ }^{61}$ 
In contrast, observational studies have consistently reported reductions in all-cause mortality for vaccinated seniors during the influenza season. ${ }^{62} \mathrm{~A}$ series of cohort studies undertaken between 1980 and 2010 showed a significant reduction in hospital admission and all-cause mortality after seasonal influenza vaccination for individuals aged 65 years and older. ${ }^{63-68}$ Indeed, studies have indicated that vaccination can be up to $43 \%$ effective in preventing influenza-related pneumonia ${ }^{67}$ and up to $70 \%$ effective in preventing hospitalization for pneumonia and influenza for older persons living in an institutional setting. ${ }^{68}$ Three quantitative reviews of cohort studies have concluded that influenza vaccination reduced pneumonia and all winter deaths attributed to influenza among community-dwelling elderly people 65 years and older by $30 \%-50 \%$ and $47 \%-68 \%,{ }^{69-71}$ respectively. These results have been taken as evidence that vaccination reduces the risk of death and influenza-related hospital admission in the elderly, ${ }^{72}$ and have led to support of senior vaccination programs as both cost-saving ${ }^{73,74}$ and cost-effective. ${ }^{68}$ However, questions have arisen about the quality and interpretation of these data. ${ }^{75-78}$ Simonsen et al ${ }^{3}$ analyzed influenza vaccine coverage and computed the estimates of influenza-related mortality and all-cause deaths for 33 influenza seasons from 1968 to 2001 in the USA elderly population. The study found no correlation between increasing vaccination coverage after 1980 and declining mortality rates in any age-group. Moreover, Simonsen and colleagues $^{3,79}$ argued that flu shots could not possibly have prevented more deaths than the $5 \%-10 \%$ of deaths that were flu-related. Assuming a vaccine effectiveness of $50 \%$ against these winter deaths with no deaths attributable to influenza outside the winter months, the maximum percentage of all-cause winter mortality that could be prevented by the influenza vaccine would be about $2 \%-5 \%$. Changes of such a small magnitude in all-cause deaths could easily be missed in ecological and observational studies. A recent Cochrane systematic review concluded that the effectiveness against influenza-like illness in aged individuals or the exact benefit of the vaccine strategy against laboratory-confirmed influenza cases could not be established, due to the likely presence of bias in nonrandomized controlled trials. ${ }^{80}$

Accurate assessment of influenza vaccine effectiveness can be a challenge due to varying case definitions of influenza, use of different clinical end points, and poor correlates of protection in immunogenicity studies. Methodological flaws that yield inconsistency in outcome measurements include (1) failure to exclude participants with conditions that impact the immune system, (2) eligible candidates previously vaccinated, and (3) those with high prevaccination titers. ${ }^{81}$ For example, higher preimmunization titers are associated with lower likelihood of a rise in antihemagglutination antibodies or seroconversion, leading to underestimation of the vaccine efficacy. ${ }^{82}$ Yet, there is no evidence that high prevaccination titers may lead to reduced effectiveness of influenza vaccine when in fact elderly subjects with high prevaccination titers showed postimmunization geometric mean titers comparable to or higher than those observed in people with low preimmunization titers. ${ }^{83,84}$ The ability to mount an immune response also differs markedly between influenza strains and among study cohorts. As antibody response is but one of several components of the immune response, in order to fully gauge vaccine efficacy in the elderly, one should take into account changes not only in the adaptive immune system's antibody response but also age-related changes in the cellular response and the activation of the innate immune system. With the extensive polymorphism penetration in Toll-like receptors, a poor antibody response to influenza vaccination presents another confounding variable unaccounted for by simply relying on chronologic age. ${ }^{85}$

\section{Additive preventive effect of influenza and pneumococcal vaccines in elderly persons}

Coinfection with Streptococcus pneumoniae and influenza has been observed in several epidemics ${ }^{86-88}$ It is speculated that the damage to the airway epithelial lining caused by influenza promotes bacterial growth, ${ }^{89-91}$ and that in turn bacterium-derived proteases enhance viral virulence. With the ongoing debate about the efficacy of influenza and pneumococcal vaccination, there have been a few trials that examined the combined effect of simultaneous influenza and pneumococcal vaccination in older adults. In a large-cohort study of Swedish patients $\geq 65$ years of age, Christenson et $\mathrm{al}^{92}$ studied the additive effectiveness of pneumococcal and influenza vaccination on a population of Stockholm residents aged 65 years and older. The study resulted in a $29 \%$ reduction in the incidence of all-cause pneumonia and a $35 \%$ reduction in the death rate from allcause pneumonia in the vaccine group..$^{92}$ Moreover, patients who were hospitalized for influenza or pneumonia after having received both vaccines had a significantly shorter mean length of stay than those who were not vaccinated. More recently, a randomized trial involving 786 Japanese individuals aged $\geq 65$ years showed a significant reduction in direct medical costs (approximately \$660) for pneumonia who received routine influenza vaccination during the first 
year following the PPV vaccinations for subjects older than 75 years of age and for those who had difficulty walking, but not for all study subjects older than 65 years. ${ }^{34}$

Several analyses have documented the cost-effectiveness of this approach. Weaver et $\mathrm{al}^{93}$ calculated the cost-effectiveness ratio for concomitant influenza vaccine and PPSV23 in the elderly to be $\$ 35,486$ per quality-adjusted life year (QALY), compared with $\$ 53,547$ per QALY for PPSV23 and \$130,908 per QALY for influenza given alone. Similarly, Cai et al ${ }^{14}$ found that for 100,000 elderly people over 65 years of age in Japan, the cost-effectiveness ratio of influenza-only vaccination was $\$ 6187$ per year of life saved, while the combined vaccination of influenza with pneumococcal was $\$ 5511$ for the same benefit.

\section{Optimizing strategies for vaccine uptake in the elderly}

The paucity of RCT data and the limitations of the cohort studies done to date make the evidence base for existing pneumococcal and influenza vaccination in older adults to prevent pneumonia marginal at best. To fill the gaps with conventional vaccines, several strategies have been investigated during the last few years, searching for innovative formulations able to offer a higher and broader immune response, or an equivalent response at a lower antigen dosage, while maintaining a good safety and bioavailability profile. . $5,96^{-}$ Three innovative vaccine approaches are currently being pursued for S. pneumoniae, as follows.

\section{Adaptation and modifications of the capsular polysaccharide conjugate vaccine} With the growing evidence of serotype replacement, expanded-valency PCVs are being tested, but the cost and the complexity of manufacture pose serious impediments. The international nonprofit organization Program for Appropriate Technology in Health (PATH) is collaborating separately with the Serum Institute of India and the China National Biotec Group's Chengdu Institute of Biological Products to speed the development of PCVs that target serotypes prevalent in underdeveloped countries and deliver these at an affordable rate, using novel techniques to reduce the cost of generating conjugates.

\section{Protein-based serotype-independent subunit vaccines}

Two well-studied examples of these include pneumococcal surface protein (Psp) PspA, and choline-binding protein (also referred to as $\mathrm{PspC}$ ). Theoretical major advantages for such forms of vaccination are serotype-independent protection, the possibility of oral or intranasal administration, and the likelihood of a less complex production process. Another formulation involves the use of full proteomic screens whereby protein libraries are evaluated for immunogenic targets. A recombinant protein vaccine derived from antigens identified through antibodies recovered from convalescent sera of patients with invasive pneumococcal disease has cleared phase I clinical trial. ${ }^{97}$

\section{Killed whole-cell pneumococcal vaccine}

Preliminary data using killed whole cells showed a robust and reproducible protection against nasopharyngeal colonization and invasive disease. ${ }^{98}$ Potential advantages of this approach include the very low cost of production, the serotypeindependent mechanisms of protection, and the possibility of conferring comprehensive immunity to colonization and invasive disease.

As for influenza vaccines, new formulations, such as increasing the dose of the trivalent inactivated vaccine, $, 99,100$ change to live attenuated vaccines, ${ }^{101}$ or virosomal vaccines, ${ }^{102}$ have been evaluated in older subjects with varying success. The addition of novel adjuvants (MF59 or AS03) to improve the immunogenicity of these vaccines ${ }^{103,104}$ has been demonstrated to be safe and well tolerated in the elderly, as reported both in phase I-IV clinical studies involving more than 14,000 individuals. Antibodies generated in this way may also be more protective against drift variants, which is important as pandemic viruses evolve.

From a health-care policy point of view, there remains the long-standing issue of how to engage both physicians and the general public in vaccination programs. Participating in vaccination programs can be expensive, and many insurance plans in developing and underdeveloped countries have poor coverage for preventive services, particularly elderly immunizations. Frailty poses barriers to vaccination, and patients (and providers) may tend to "give up" on preventive measures near the end of life. The antivaccine movement may also contribute to the fear of adverse events. Although serious adverse events due to vaccination are rare and are limited to fever and mild, local reactions at the injection site, media attention to rare adverse events increases public awareness of their occurrence and may decrease receptivity to vaccination.

The success of a vaccination program will require political will to put pneumonia prevention a priority on the national health agenda and an intricate collaboration between health agencies and health-care facilities to assure that vaccines reach all elderly patients in order to stay ahead of the bacteria 
and viruses that are known to be vaccine-preventable. One model of health organization that showed high success in vaccination against pneumonia pathogens is the Veterans Administration (VA). The VA has the highest immunization rates, with similar rates among blacks and whites. This may be explained by its use of a multimodal program to increase rates, including patient reminders, standing orders, freestanding vaccination clinics, and assessment of vaccination rates with feedback and incentives to clinicians. ${ }^{105}$

\section{Conclusion}

As the population of older adults and the prevalence of underlying medical conditions that complicate the course of pneumonia increases, hospitalizations for pneumonia are likely to continue to rise unless effective intervention strategies are implemented. Current US strategies to prevent pneumonia among older adults include recommending immunization with PPV and annual influenza vaccinations. However, the effectiveness of these vaccines decreases with increasing age and among individuals with comorbid conditions. In the absence of RCTs and the unlikely event that RCTs will be conducted with the currently licensed vaccines, additional strategies, such as more effective vaccines for older individuals and new vaccines for common pathogens, will likely be necessary. Further research to gain deeper insight into basic mechanisms of immunosenescence, adaptation of vaccination strategies, and development of new modes of administration and adjuvants will help to achieve optimal protection in old age against the "Captain of the men of death."

\section{Disclosure}

AES has served as a consultant for Pfizer.

\section{References}

1. Silverman ME, Murray TJ, Bryan CS. The Quotable Osler. Philadelphia: American College of Physicians; 1998:139.

2. Heron M, Tejada-Vera B. Deaths: leading causes for 2005. Natl Vital Stat Rep. 2009;58(8):1-97.

3. Simonsen L, Reichert TA, Viboud C, Blackwelder WC, Taylor RJ, Miller MA. Impact of influenza vaccination on seasonal mortality in the US elderly population. Arch Intern Med. 2005;165(3):265-272.

4. Centers for Disease Control and Prevention. Estimates of deaths associated with seasonal influenza - United States, 1976-2007. MMWR Morb Mortal Wkly Rep. 2010;59(33):1057-1062.

5. Beigel JH. Influenza. Crit Care Med. 2008;36(9):2660-2666.

6. Thomas CP, Ryan M, Chapman JD, et al. Incidence and cost of pneumonia in Medicare beneficiaries. Chest. Epub March 8, 2012.

7. Fedson DS, Musher DM. Pneumococcal polysaccharide vaccine. In: Plotkin SA, Orenstein WA, editors. Vaccines. Philadelphia: Saunders; 2003:529-588.

8. Sankilampi U, Honkanen PO, Bloigu A, Herva E, Leinonen M. Antibody response to pneumococcal capsular polysaccharide vaccine in the elderly. J Infect Dis. 1996;173(2):387-393.
9. Lai CC, Lee LN, Yu CJ, et al. Antibody responses to pneumococcal polysaccharide vaccine in Taiwanese patients with chronic obstructive pulmonary disease. J Formos Med Assoc. 2007;106(3):196-203.

10. Schenkein JG, Park S, Nahm MH. Pneumococcal vaccination in older adults induces antibodies with low opsonic capacity and reduced antibody potency. Vaccine. 2008;26(43):5521-5526.

11. Rubins JB, Puri AK, Loch J, et al. Magnitude, duration, quality, and function of pneumococcal vaccine responses in elderly adults. $J$ Infect Dis. 1998;178(2):431-440.

12. Romero-Steiner S, Musher DM, Cetron MS, et al. Reduction in functional antibody activity against Streptococcus pneumoniae in vaccinated elderly individuals highly correlates with decreased IgG antibody avidity. Clin Infect Dis. 1999;29(2):281-288.

13. Ortqvist A. Pneumococcal vaccination: current and future issues. Eur Respir J. 2001;18(1):184-195.

14. Musher DM, Manof SB, Liss C, et al. Safety and antibody response, including antibody persistence for 5 years, after primary vaccination or revaccination with pneumococcal polysaccharide vaccine in middleaged and older adults. $J$ Infect Dis. 2010;201(4):516-524.

15. Manoff SB, Liss C, Caulfield MJ, et al. Revaccination with a 23 -valent pneumococcal polysaccharide vaccine induces elevated and persistent functional antibody responses in adults aged $65>$ or $=$ years. $J$ Infect Dis. 2010;201(4):525-533.

16. O’Brien KL, Hochman M, Goldblatt D. Combined schedules of pneumococcal conjugate and polysaccharide vaccines: is hyporesponsiveness an issue? Lancet Infect Dis. 2007;7(9):597-606.

17. de Roux A, Schmole-Thoma B, Siber GR, et al. Comparison of pneumococcal conjugate polysaccharide and free polysaccharide vaccines in elderly adults: conjugate vaccine elicits improved antibacterial immune responses and immunological memory. Clin Infect Dis. 2008;46(7):1015-1023.

18. Moberley SA, Holden J, Tatham DP, Andrews RM. Vaccines for preventing pneumococcal infection in adults. Cochrane Database Syst Rev. 2008;(1):CD000422.

19. Shapiro ED, Clemens JD. A controlled evaluation of the protective efficacy of pneumococcal vaccine for patients at high risk of serious pneumococcal infections. Ann Intern Med. 1984;101(3):325-330.

20. Sims RV, Steinmann WC, McConville JH, King LR, Zwick WC, Schwartz JS. The clinical effectiveness of pneumococcal vaccine in the elderly. Ann Intern Med. 1988;108(5):653-657.

21. Melegaro A, Edmunds WJ. The 23-valent pneumococcal polysaccharide vaccine. Part I. Efficacy of PPV in the elderly: a comparison of meta-analyses. Eur J Epidemiol. 2004;19(4):353-363.

22. Kaufman P. Pneumonia in old age; active immunization against pneumonia with pneumonococcus polysaccharide; results of a six year study. Arch Intern Med. 1947;79(5):518-531.

23. Gaillat J, Zmirou D, Mallaret MR, et al. Clinical trial of an antipneumococcal vaccine in elderly subjects living in institutions. Rev Epidemiol Sante Publique. 1985;33(6):437-444. French.

24. Honkanen PO, Keistinen T, Miettinen L, et al. Incremental effectiveness of pneumococcal vaccine on simultaneously administered influenza vaccine in preventing pneumonia and pneumococcal pneumonia among persons aged 65 years or older. Vaccine. 1999;17(20-21):2493-2500.

25. Vila-Corcoles A, Ochoa-Gondar O, Hospital I, et al. Protective effects of the 23-valent pneumococcal polysaccharide vaccine in the elderly population: the EVAN-65 study. Clin Infect Dis. 2006;43(7):860-868.

26. Vila-Corcoles A, Salsench E, Rodriguez-Blanco T, et al. Clinical effectiveness of 23-valent pneumococcal polysaccharide vaccine against pneumonia in middle-aged and older adults: a matched case-control study. Vaccine. 2009;27(10):1504-1510.

27. Jackson LA, Neuzil KM, Yu O, et al. Effectiveness of pneumococcal polysaccharide vaccine in older adults. $N$ Engl J Med. 2003;348(18): $1747-1755$.

28. Johnstone J, Eurich DT, Minhas JK, Marrie TJ, Majumdar SR. Impact of the pneumococcal vaccine on long-term morbidity and mortality of adults at high risk for pneumonia. Clin Infect Dis. 2010;51(1): $15-22$. 
29. Riley ID, Lehmann D, Alpers MP, Marshall TF, Gratten H, Smith D. Pneumococcal vaccine prevents death from acute lower-respiratorytract infections in Papua New Guinean children. Lancet. 1986;2(8512):877-881.

30. Wagner C, Popp W, Posch M, Vlasich C, Rosenberger-Spitzy A. Impact of pneumococcal vaccination on morbidity and mortality of geriatric patients: a case-controlled study. Gerontology. 2003;49(4): 246-250.

31. Melegaro A, Edmunds WJ. The 23-valent pneumococcal polysaccharide vaccine. Part II. A cost-effectiveness analysis for invasive disease in the elderly in England and Wales. Eur J Epidemiol. 2004;19(4): 365-375.

32. Simberkoff MS, Cross AP, Al-Ibrahim M, et al. Efficacy of pneumococcal vaccine in high-risk patients. Results of a Veterans Administration Cooperative Study. N Engl J Med. 1986;315(21):1318-1327.

33. Austrian R. Surveillance of Pneumococcal Infection for Field Trials of Polyvalent Pneumococcal Vaccines. Bethesda: National Institutes of Health; 1980.

34. Kawakami K, Ohkusa Y, Kuroki R, et al. Effectiveness of pneumococcal polysaccharide vaccine against pneumonia and cost analysis for the elderly who receive seasonal influenza vaccine in Japan. Vaccine. 2010; 28(43):7063-7069.

35. Maruyama T, Taguchi O, Niederman MS, et al. Efficacy of 23-valent pneumococcal vaccine in preventing pneumonia and improving survival in nursing home residents: double blind, randomised and placebo controlled trial. BMJ. 2010;340:c1004.

36. Koivula I, Sten M, Leinonen M, Makela PH. Clinical efficacy of pneumococcal vaccine in the elderly: a randomized, single-blind population-based trial. Am J Med. 1997;103(4):281-290.

37. Ortqvist A, Hedlund J, Burman LA, et al. Randomised trial of 23-valent pneumococcal capsular polysaccharide vaccine in prevention of pneumonia in middle-aged and elderly people. Swedish Pneumococcal Vaccination Study Group. Lancet. 1998;351(9100):399-403.

38. Alfageme I, Vazquez R, Reyes N, et al. Clinical efficacy of antipneumococcal vaccination in patients with COPD. Thorax. 2006;61(3): 189-195.

39. Hirschmann JV, Lipsky BA. The pneumococcal vaccine after 15 years of use. Arch Intern Med. 1994;154(4):373-377.

40. Jackson LA, Janoff EN. Pneumococcal vaccination of elderly adults: new paradigms for protection. Clin Infect Dis. 2008;47(10): $1328-1338$.

41. Dear K, Holden J, Andrews R, Tatham D. Vaccines for preventing pneumococcal infection in adults. Cochrane Database Syst Rev. 2003;(4): CD000422.

42. Huss A, Scott P, Stuck AE, Trotter C, Egger M. Efficacy of pneumococcal vaccination in adults: a meta-analysis. CMAJ. 2009;180(1):48-58.

43. Arguedas A, Soley C, Abdelnour A. Prevenar experience. Vaccine. 2011;29 Suppl 3:C26-C34.

44. Dagan R, Gradstein S, Belmaker I, et al. An outbreak of Streptococcus pneumoniae serotype 1 in a closed community in southern Israel. Clin Infect Dis. 2000;30(2):319-321.

45. Romney MG, Hull MW, Gustafson R, et al. Large community outbreak of Streptococcus pneumoniae serotype 5 invasive infection in an impoverished, urban population. Clin Infect Dis. 2008;47(6): $768-774$.

46. Hausdorff WP. The roles of pneumococcal serotypes 1 and 5 in paediatric invasive disease. Vaccine. 2007;25(13):2406-2412.

47. Prevnar 13 (pneumococcal 13-valent conjugate vaccine [diphtheria CRM197 protein]). Philadelphia, PA: Wyeth Pharmaceuticals; 2011.

48. Food and Drug Administration. Vaccines and Related Biological Products Advisory Committee (VRBPAC) adult indication briefing document: Prevnar 13. Silver Spring, MD: US Department of Health and Human Services, Food and Drug Administration; 2011. Available from: http://www.fda.gov/downloads/advisorycommittees/ committeesmeetingmaterials/bloodvaccinesandotherbiologics/ vaccinesandrelatedbiologicalproductsadvisorycommittee/ucm 279680 . pdf. Accessed October 12, 2012.
49. Centers for Disease Control and Prevention. Licensure of 13-valent pneumococcal conjugate vaccine for adults aged 50 years and older. MMWR Morb Mortal Wkly Rep. 2012;61(21):394-395.

50. Hak E, Grobbee DE, Sanders EA, et al. Rationale and design of CAPITA: a RCT of 13-valent conjugated pneumococcal vaccine efficacy among older adults. Neth J Med. 2008;66(9):378-383.

51. Pilishvili T, Lexau C, Farley MM, et al. Sustained reductions in invasive pneumococcal disease in the era of conjugate vaccine. $J$ Infect Dis. 2010;201(1):32-41.

52. Choi YH, Jit M, Flasche S, Gay N, Miller E. Mathematical modelling long-term effects of replacing Prevnar7 with Prevnar13 on invasive pneumococcal diseases in England and Wales. PloS One. 2012;7(7): e39927.

53. Rubin JL, McGarry LJ, Strutton DR, et al. Public health and economic impact of the 13-valent pneumococcal conjugate vaccine (PCV13) in the United States. Vaccine. 2010;28(48):7634-7643.

54. Stuart WH, Dull HB, Newton LH, McQueen JL, Schiff ER. Evaluation of monovalent influenza vaccine in a retirement community during the epidemic of 1965-1966. JAMA. 1969;209(2):232-238.

55. Burney LE. Influenza immunization: statement. Public Health Rep. 1960;75(10):944.

56. Long PH. Recommendations for influenza immunization and control: 1964-1965. Med Times. 1964;92:1203-1205.

57. Govaert TM, Thijs CT, Masurel N, Sprenger MJ, Dinant GJ, Knottnerus JA. The efficacy of influenza vaccination in elderly individuals. A randomized double-blind placebo-controlled trial. JAMA. 1994;272(21):1661-1665.

58. Goodwin K, Viboud C, Simonsen L. Antibody response to influenza vaccination in the elderly: a quantitative review. Vaccine. 2006;24(8): 1159-1169.

59. Allsup S, Haycox A, Regan M, Gosney M. Is influenza vaccination cost effective for healthy people between ages 65 and 74 years? A randomised controlled trial. Vaccine. 2004;23(5):639-645.

60. Praditsuwan R, Assantachai P, Wasi C, Puthavatana P, Kositanont U. The efficacy and effectiveness of influenza vaccination among Thai elderly persons living in the community. J Med Assoc Thai. 2005;88(2): 256-264.

61. Treanor JD. Influenza - the goal of control. $N$ Engl J Med. 2007;357(14):1439-1441.

62. Nichol KL. Challenges in evaluating influenza vaccine effectiveness and the mortality benefits controversy. Vaccine. 2009;27(45): 6305-6311.

63. Nordin J, Mullooly J, Poblete S, et al. Influenza vaccine effectiveness in preventing hospitalizations and deaths in persons 65 years or older in Minnesota, New York, and Oregon: data from 3 health plans. J Infect Dis. 2001;184(6):665-670.

64. Hak E, Wei F, Grobbee DE, Nichol KL. A nested case-control study of influenza vaccination was a cost-effective alternative to a full cohort analysis. J Clin Epidemiol. 2004;57(9):875-880.

65. de Diego C, Vila-Corcoles A, Ochoa O, et al. Effects of annual influenza vaccination on winter mortality in elderly people with chronic heart disease. Eur Heart J. 2009;30(2):209-216.

66. Campitelli MA, Rosella LC, Stukel TA, Kwong JC. Influenza vaccination and all-cause mortality in community-dwelling elderly in Ontario, Canada, a cohort study. Vaccine. 2010;29(2):240-246.

67. Monto AS, Hornbuckle K, Ohmit SE. Influenza vaccine effectiveness among elderly nursing home residents: a cohort study. Am J Epidemiol. 2001;154(2):155-160.

68. Nichol KL, Nordin JD, Nelson DB, Mullooly JP, Hak E. Effectiveness of influenza vaccine in the community-dwelling elderly. N Engl J Med. 2007;357(14):1373-1381

69. Vu T, Farish S, Jenkins M, Kelly H. A meta-analysis of effectiveness of influenza vaccine in persons aged 65 years and over living in the community. Vaccine. 2002;20(13-14):1831-1836.

70. Rivetti D, Jefferson T, Thomas R, et al. Vaccines for preventing influenza in the elderly. Cochrane Database Syst Rev. 2006;(3): CD004876. 
71. Jefferson T, Rivetti D, Rivetti A, Rudin M, Di Pietrantonj C, Demicheli V. Efficacy and effectiveness of influenza vaccines in elderly people: a systematic review. Lancet. 2005;366(9492):1165-1174.

72. Fiore AE, Shay DK, Broder K, et al. Prevention and control of influenza: recommendations of the Advisory Committee on Immunization Practices (ACIP), 2008. MMWR Recomm Rep. 2008;57(RR-7):1-60.

73. Deans GD, Stiver HG, McElhaney JE. Influenza vaccines provide diminished protection but are cost-saving in older adults. J Intern Med. 2010;267(2):220-227.

74. Maciosek MV, Solberg LI, Coffield AB, Edwards NM, Goodman MJ. Influenza vaccination health impact and cost effectiveness among adults aged 50 to 64 and 65 and older. Am J Prev Med. 2006;31(1):72-79.

75. Jefferson T. Influenza vaccination: policy versus evidence. BMJ. 2006;333(7574):912-915.

76. Fireman B, Lee J, Lewis N, Bembom O, van der Laan M, Baxter R. Influenza vaccination and mortality: differentiating vaccine effects from bias. Am J Epidemiol. 2009;170(5):650-656.

77. Simonsen L, Viboud C, Taylor RJ, Miller MA, Jackson L. Influenza vaccination and mortality benefits: new insights, new opportunities. Vaccine. 2009;27(45):6300-6304.

78. Jackson ML, Nelson JC, Weiss NS, Neuzil KM, Barlow W, Jackson LA. Influenza vaccination and risk of community-acquired pneumonia in immunocompetent elderly people: a population-based, nested casecontrol study. Lancet. 2008;372(9636):398-405

79. Simonsen L, Taylor RJ, Viboud C, Miller MA, Jackson LA. Mortality benefits of influenza vaccination in elderly people: an ongoing controversy. Lancet Infect Dis. 2007;7(10):658-666.

80. Jefferson T, Di Pietrantonj C, Rivetti A, Bawazeer GA, Al-Ansary LA, Ferroni E. Vaccines for preventing influenza in healthy adults. Cochrane Database Syst Rev. 2010;(7):CD001269.

81. Skowronski DM, Tweed SA, De Serres G. Rapid decline of influenza vaccine-induced antibody in the elderly: is it real, or is it relevant? J Infect Dis. 2008;197(4):490-502.

82. Feng J, Gulati U, Zhang X, et al. Antibody quantity versus quality after influenza vaccination. Vaccine. 2009;27(45):6358-6362.

83. Ansaldi F, Bacilieri S, Durando P, et al. Cross-protection by MF59adjuvanted influenza vaccine: neutralizing and haemagglutinationinhibiting antibody activity against $\mathrm{A}(\mathrm{H} 3 \mathrm{~N} 2)$ drifted influenza viruses. Vaccine. 2008;26(12):1525-1529

84. Ansaldi F, Zancolli M, Durando P, et al. Antibody response against heterogeneous circulating influenza virus strains elicited by MF59- and non-adjuvanted vaccines during seasons with good or partial matching between vaccine strain and clinical isolates. Vaccine. 2010;28(25): 4123-4129.

85. Panda A, Qian F, Mohanty S, et al. Age-associated decrease in TLR function in primary human dendritic cells predicts influenza vaccine response. J Immunol. 2010;184(5):2518-2527.

86. Nuzum J, Pilote I, Stangl F, Bonar B. Pandemic influenza and pneumonia in a large civilian hospital. JAMA. 1918;71:1562-1565.

87. Schwarzmann SW, Adler JL, Sullivan RJ Jr, Marine WM. Bacterial pneumonia during the Hong Kong influenza epidemic of 1968-1969. Arch Intern Med. 1971;127(6):1037-1041.

88. Palacios G, Hornig M, Cisterna D, et al. Streptococcus pneumoniae coinfection is correlated with the severity of H1N1 pandemic influenza. PloS One. 2009;4(12):e8540.

Clinical Interventions in Aging

\section{Publish your work in this journal}

Clinical Interventions in Aging is an international, peer-reviewed journal focusing on evidence-based reports on the value or lack thereof of treatments intended to prevent or delay the onset of maladaptive correlates of aging in human beings. This journal is indexed on PubMed Central, MedLine, the American Chemical Society's 'Chemical Abstracts
89. McCullers JA. Insights into the interaction between influenza virus and pneumococcus. Clin Microbiol Rev. 2006;19(3):571-582.

90. Diavatopoulos DA, Short KR, Price JT, et al. Influenza A virus facilitates Streptococcus pneumoniae transmission and disease. FASEB J. 2010;24(6):1789-1798.

91. Morens DM, Taubenberger JK, Fauci AS. Predominant role of bacterial pneumonia as a cause of death in pandemic influenza: implications for pandemic influenza preparedness. J Infect Dis. 2008;198(7): 962-970.

92. Christenson B, Hedlund J, Lundbergh P, Ortqvist A. Additive preventive effect of influenza and pneumococcal vaccines in elderly persons. Eur Respir J. 2004;23(3):363-368.

93. Weaver M, Krieger J, Castorina J, Walls M, Ciske S. Cost-effectiveness of combined outreach for the pneumococcal and influenza vaccines. Arch Intern Med. 2001;161(1):111-120.

94. Cai L, Uchiyama H, Yanagisawa S, Kamae I. Cost-effectiveness analysis of influenza and pneumococcal vaccinations among elderly people in Japan. Kobe J Med Sci. 2006;52(3-4):97-109.

95. Lambert LC, Fauci AS. Influenza vaccines for the future. $N$ Engl J Med. 2010;363(21):2036-2044.

96. Nabel GJ, Fauci AS. Induction of unnatural immunity: prospects for a broadly protective universal influenza vaccine. Nat Med. 2010;16(12): 1389-1391.

97. Giefing C, Meinke AL, Hanner M, et al. Discovery of a novel class of highly conserved vaccine antigens using genomic scale antigenic fingerprinting of pneumococcus with human antibodies. J Exp Med. 2008;205(1):117-131.

98. Lu YJ, Leite L, Goncalves VM, et al. GMP-grade pneumococcal whole-cell vaccine injected subcutaneously protects mice from nasopharyngeal colonization and fatal aspiration-sepsis. Vaccine. 2010;28(47):7468-7475.

99. Cate TR, Rayford Y, Nino D, et al. A high dosage influenza vaccine induced significantly more neuraminidase antibody than standard vaccine among elderly subjects. Vaccine. 2010;28(9):2076-2079.

100. Falsey AR, Treanor JJ, Tornieporth N, Capellan J, Gorse GJ. Randomized, double-blind controlled phase 3 trial comparing the immunogenicity of high-dose and standard-dose influenza vaccine in adults 65 years of age and older. J Infect Dis. 2009;200(2):172-180.

101. De Villiers PJ, Steele AD, Hiemstra LA, et al. Efficacy and safety of a live attenuated influenza vaccine in adults 60 years of age and older. Vaccine. 2009;28(1):228-234.

102. Huckriede A, Bungener L, Stegmann T, et al. The virosome concept for influenza vaccines. Vaccine. 2005;23 Suppl 1:S26-S38.

103. Bernstein DI, Edwards KM, Dekker CL, et al. Effects of adjuvants on the safety and immunogenicity of an avian influenza $\mathrm{H} 5 \mathrm{~N} 1$ vaccine in adults. $J$ Infect Dis. 2008;197(5):667-675.

104. Chu DW, Hwang SJ, Lim FS, et al. Immunogenicity and tolerability of an AS03(A)-adjuvanted prepandemic influenza vaccine: a phase III study in a large population of Asian adults. Vaccine. 2009;27(52): 7428-7435.

105. Jha AK, Wright SM, Perlin JB. Performance measures, vaccinations, and pneumonia rates among high-risk patients in Veterans Administration health care. Am J Public Health. 2007;97(12):2167-2172.

\section{Dovepress}

Service' (CAS), Scopus and the Elsevier Bibliographic databases. The manuscript management system is completely online and includes a very quick and fair peer-review system, which is all easy to use. Visit http://www.dovepress.com/testimonials.php to read real quotes from published authors. 